\title{
Sodium Arsenic Alters the Gene Expression of some Steroidogenic Genes in TM3 Leydig Cell
}

\author{
Tunahan Taş̧ $1^{1 *}$, Vahap Eldem², Melike Erkan² \\ ${ }^{1}$ Vocational School of Health Services, Istanbul Bilgi University, Istanbul, Turkey \\ ${ }^{2}$ Department of Biology, Faculty of Science, Istanbul University, Istanbul, Turkey \\ "tunahan.tasci@bilgi.edu.tr
}

Received: 15 March 2019

Accepted: 17 September 2019

DOI: $10.18466 /$ cbayarfbe. 540544

\begin{abstract}
Arsenic is a broad-spectrum environmental contaminant with mutagenic, teratogenic and carcinogenic effects. Due to its widespread distribution in nature, drinking water is the most common source of arsenic exposure for the general population. In this study, we aimed to determine the effect of sodium arsenite on the viability and expression profile of steroidogenic genes in TM3 Leydig cells, responsible for testicular steroidogenesis. The TM3 Leydig cells were treated with sodium arsenic $(384,8 \mu \mathrm{M}$ or $7,6 \mathrm{mM})$ for 24 hours with LH (Luteinizing hormone) stimulation. The MTT assay was used for measuring cell viability, the expression level of key genes of the steroidogenesis was evaluated using RT-qPCR.The MTT assay showed that cell viability was decreased dose-dependently. RT-qPCR demonstrated that the expression level of CYP11A1, CYP17A1 were decreased as compared to the untreated control while StAR gene expression was found to be surprisingly high in the cell exposed to high-dose arsenic $(p<0.05)$. The expression profile of two dehydrogenase; $17 \beta-\mathrm{HSD}$ and $3 \beta-\mathrm{HSD}$ was significantly reduced in high dose arsenic treated-group $(p<0.05)$; but however, no statistical significance was found in low-dose. The RTqPCR also showed that the expression SF-1 (Steroidogenic factor-1), a key regulator of adrenal and reproductive development, was significantly decreased in both low-dose and high-dose $(p<0.05)$. Arsenic toxicity in Leydig cell leads to cell viability loss and cause a perturbation in key steroidogenic genes, reflecting the possible role of arsenic in infertility and male reproductive system disorders.
\end{abstract}

Keywords: Arsenic, Gene Expression, Leydig Cell, Steroidogenesis, Viability.

\section{Introduction}

Heavy metals are environmental toxins that are found everywhere in nature [1]. Among them, arsenic is widely available worldwide and can be detected everywhere. Recent studies showed that all arsenic compounds are toxic; particularly inorganic forms are highly toxic [2-3]. Currently, arsenic compounds are used in the production of agricultural pesticides, metallurgy materials and various manufacturing works such as glass production. Drinking water is the most common source of arsenic exposure for human and the arsenic $\left(\mathrm{NaAsO}_{2}\right)$ concentrations in drinking water was found to be between $384.8 \mu \mathrm{M}(50 \mathrm{ppm})$ and $7.6 \mathrm{mM}(1000 \mathrm{ppm})$ as the lower and upper limits in drinking waters of various regions of the world. Arsenic is a common environmental pollutant with mutagenic, teratogenic and carcinogenic effects. Despite many efforts, the true mechanism of arsenic toxicity has not been fully explained yet [3]. Accumulating evidence showed that arsenic toxicity is indicative of oxidative stress suggests that central proteins in the redox signaling and control pathway interact with thiol groups [4]. Besides, arsenic causes an increase in the amount of reactive oxygen radicals in the cell by electron transition. Animal cells exposed to environmental stress produce these reactive oxygen radicals and when these radicals are produced in high amounts in the cell; they repress their neutralization mechanisms and increase oxidative stress. Oxidative stress is among the major factors causing disorders in male reproductive system [3-5]. Recent studies also showed that arsenic exposure alters the gene expression pattern, for instance steroid-associated genes, cytokines, apoptosis-associated genes and cell cycle genes. Arsenic has also adverse effects on male reproductive system leading to reproductive dysfunctions. Interstitial or Leydig cells are the major source of testicular androgens in the male mammal and produce testosterone in the presence of luteinizing hormone. Testosterone is produced via steroidogenic pathway including key enzymes; StAR, CYP11A1, CYP17A1, HSD3B and HSD17B and transcription factors; SF-1, GATA-4 and NURR77. The aberrant expression of these genes coding for components of steroidogenic pathway could be associated with male infertility. 
To establish potential effects of arsenic on testosterone biosynthesis, we evaluated the expression level of some steroidogenic genes in response to low and high dose arsenic treatment in TM3 Leydig cell and also measured the cell viability $[5,6]$.

\section{Materials and Methods}

\subsection{Cell culture and treatment}

The TM3 is a non-tumoral cell line was derived from Leydig cells of cell line 11-13 day old mice and provided by the American Type Culture Collection (ATCC ${ }^{\circledR}$ CRL$\left.1714^{\mathrm{TM}}\right)$. The TM3 cells were resuspended in 50:50 DMEM/F12 culture medium, supplemented with 5\% Horse Serum, 2.5\% Fetal Bovine Serum, $2.5 \mathrm{mM} \mathrm{L}$ Glutamine, $0.5 \mathrm{mM}$ Sodium Pyruvate, $1.2 \mathrm{~g} / 1$ Sodium Bicarbonate, $15 \mathrm{mM}$ HEPES and PSA (PenicillinStreptomycin-Amphotericin), humidified medium containing $5 \% \mathrm{CO}_{2}$ and $95 \%$ air incubated at $37{ }^{\circ} \mathrm{C}$. The cells $\left(1 \times 10^{6}\right)$ are placed in well plates and allowed to stand for 24 hours. After adhesion, growth medium is removed and the cells are incubated for one hour in serum-free medium. Water soluble and inorganic arsenic compound sodium arsenic $\left(\mathrm{NaAsO}_{2}\right.$ (CAS Number: 7784-46-5) purity 96.6\%, Sigma-Aldrich) was prepared in serum-free medium at doses of $384.8 \mu \mathrm{M}$ and $7.6 \mathrm{mM}$. In the control group, only serum-free medium was applied. After one-hour serum-free medium treatment, arsenic and $\mathrm{LH}$ serum free assay medium are replaced (100 ng/ml LH, $384.8 \mu \mathrm{M}$ arsenic with $100 \mathrm{ng} / \mathrm{ml} \mathrm{LH}$ and $7.6 \mathrm{mM}$ arsenic with $100 \mathrm{n} / \mathrm{ml} \mathrm{LH}$ ).

\subsection{MTT cell viability assay}

The TM3 cells were seeded at 5000 cells/100 $\mu$ l well in 96 wells culture dishes for MTT (Sigma-Aldrich) cell viability assay. Subsequently, two different doses of sodium arsenic prepared in serum-free medium were incubated in the $\mathrm{CO}_{2}$ incubator at $37^{\circ} \mathrm{C}$ for 24 hours

Table 1. Primer sequences used for qPCR [20]
Gene
Primer F
Primer R

\begin{tabular}{|c|c|}
\hline StAR & CGAAACCCTAGTCAGGCACA \\
\hline CYP11A1 & CGTGACCAGAAAAGACAACA \\
\hline CYP17A1 & CATCCCACACAAGGCTAACAT \\
\hline $3 \beta-H S D$ & TAGTATTGCTTTTATTTCCCCCT \\
\hline $17 \beta$-HSD & TGGGGCTGGAGGGAGAGT \\
\hline SF-1 & GCCCTGTTGGATTACACCTTG \\
\hline Nur77 & CGGGATCCGCTACTACCTAGCTTAGTC \\
\hline GATA-4 & $\begin{array}{l}\text { AC } \Gamma \\
\text { СTCTGGAGGCGAGATGGGAC }\end{array}$ \\
\hline B-ACTIN & CGTTGACATCCGTAAAGAC \\
\hline
\end{tabular}

under LH stimulation conditions. Then, $10 \mu \mathrm{l}$ MTT solution was added to each well and the culture dishes were incubated for 4 hours at $37^{\circ} \mathrm{C}$ in a $\mathrm{CO}_{2}$ incubator so that the MTT dye could be converted into water-insoluble normalization. formazan crystals. The optical densities of the cells were read at $540 \mathrm{~nm}$ in the ELISA. Control cell viability not treated with the test substance was taken as $100 \%$, and the survival rates of the test cells were expressed as a percentage. This test was repeated 3 times.

\subsection{Total RNA extraction, cDNA conversion and quantitative PCR analysis}

Total RNA was isolated from control and arsenicexposed TM3 cells ( $2 \times 10^{6}$ cells for each group) using TRIzol reagent (Invitrogen, Carlsbad, CA) based on manufacturer's protocol. The purity and integrity of the isolated RNA samples was measured using a NanoDrop 2000 spectrophotometer (Thermo Fisher Scientific). The calculated yield of total RNA was ranged from 628.6 to $874.8 \mathrm{ng} / \mu 1$ per $2 \times 10^{6}$ Leydig cell group with A260/A280 ratio of 1.81-1.89. Following RNA extraction, the synthesis of cDNA was performed using $10 \mu \mathrm{g}$ of total RNA and the Script cDNA Synthesis Kit (Jena Bioscience, Jena, Germany). Briefly, $10 \mu \mathrm{g}$ of the RNA extract was added to $8 \mu \mathrm{L}$ cDNA synthesis mixture containing $4 \mu \mathrm{L}$ of $5 \mathrm{X}$ SCRIPT RT buffer complete, $1 \mu \mathrm{L}$ of $10 \mathrm{mM}$ dNTP mix, $1 \mu \mathrm{L}$ of 40 units of RNase inhibitor, $1 \mu \mathrm{L}$ of $100 \mathrm{mM}$ DTT, $0.5 \mu \mathrm{L}$ of $100 \mu \mathrm{M}$ random hexamers and $0.5 \mu \mathrm{L}$ of 200 units of SCRIPT reverse transcriptase. The mixture was incubated at $42{ }^{\circ} \mathrm{C}$ for 10 minutes, followed by $50{ }^{\circ} \mathrm{C}$ for 60 minutes in a Techne Thermal Cycler.

Real-time quantitative PCR (RT-qPCR) was carried out using SCRIPT One-Step RT-PCR Kit (EvaGreen, Jena Bioscience) with a Roche RT-qPCR instrument (Roche LC480). In total, $50 \mathrm{ng}$ cDNA were used for the RTqPCR and the reactions were performed in $25 \mu \mathrm{L}$ final volume and RT-qPCR conditions: $95^{\circ} \mathrm{C}$ for $10 \mathrm{~min}$ and followed by 35 cycles of $95^{\circ} \mathrm{C}$ for $15 \mathrm{~s}$ and $60^{\circ} \mathrm{C}$ for 1 min. All primer pairs for StAR, CYP11A1, CYP17A1, HSD3B, HSD17B, SF-1, Nur77 and GATA-4 genes were
TGTCTCACTGTGGTCCAAGC

AGGATGAAGGAGAGGAGAGC

CTCCGAAGGGCAAATAACTG

ATTTATTGCTGTTTTTGTTTTGC

TATTTGGGGGGAGGGGTTC

GTTGCCAAATGCTTGTGGTA

CTGGTACCGCGTGCGCTCTGCAATCCT
Tr
CGTCGTCACTTCTCTACGCG

TGGAAGGTGGACAGTGAG

obtained from previous studies (Table 1) [20]. The $\beta$ actin gene was chosen as a reference gene for 


\section{Statistical analysis}

For the MTT cell viability assay, statistical analysis was performed using GraphPad Prism 6 software (GraphPad Software, San Diego, CA, USA) and analysis of variance was used for comparisons among all groups. The data was calculated by a one way ANOVA with Tukey's multiple comparisons test. The analysis results were expressed as mean \pm standard error and values of $p<0.001$ and $p<0.01$ were considered statistically significant. For determining the significance of RT-qPCR data, Student's $t$ test was performed using Excel software and the values are the mean $\pm \mathrm{SE}$ from three samples and significant differences were indicated as $(*) p<0.05$, and $(* *) p<0.01$. All experiments were done in triplicate and RT-qPCR graphs were drawn by Excel.

\section{Results and Discussion}

The effects of arsenic on the proliferation rates of TM3 cells were analyzed by counting the cells left in the arsenic exposure $(384,8 \mu \mathrm{M}$ or $7,6 \mathrm{mM})$ after 24 hours. The MTT assay showed that the cell viability reduction was observed at both doses $(384,8 \mu \mathrm{M}$ or $7,6 \mathrm{mM})$ (Figure 1). The highest decrease in cell viability (24\% decrease) was observed at 7,6 $\mathrm{mM}$ dose. In general, the declining tendency in concentration-dependent cell viability was monitored from $384,8 \mu \mathrm{M}$ to $7,6 \mathrm{mM}$ (Figure 1).

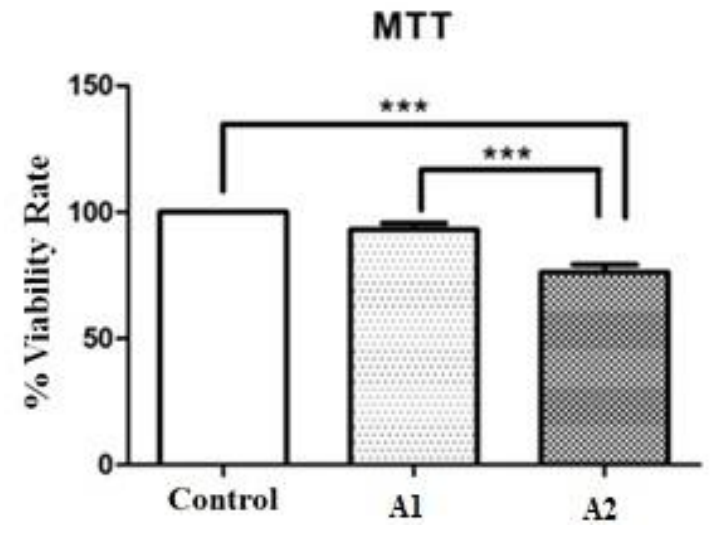

Figure 1. Effect of sodium arsenite on the viability of TM3 cells $(* * * p<0.001)$.

The effects of arsenic on the expression level of steroidogenic genes (StAR, CYP11A1, CYP17A1, HSD3B and HSD17B) and transcription factors (SF-1, Nur77 and GATA-4) were evaluated using RT-qPCR. Expression analysis indicated that the StAR expression, the rate-determining step in the steroidogenic pathway, was 13 fold $(p<0.01)$ higher in the low-dose and 6 fold $(p<0.05)$ higher in the high-dose compared to the control (Figure 2a). The expression of CYP17A1 encoding P450 $17 \alpha$-hydroxylase enzyme was reduced at low and high arsenic doses (Figure 2c). As for CYP11A1 encoding cytochrome $\mathrm{P} 450$ cholesterol side chain cleavage enzyme, its expression level was reduced by at least 2 fold $(p<0.05)$ at low-dose $(384,8 \mu \mathrm{M})$, but however intriguing, the expression was not changed significantly at high dose $(7,6 \mathrm{mM})$ in spite of repeating the experiment several times (Figure $2 b$ ).

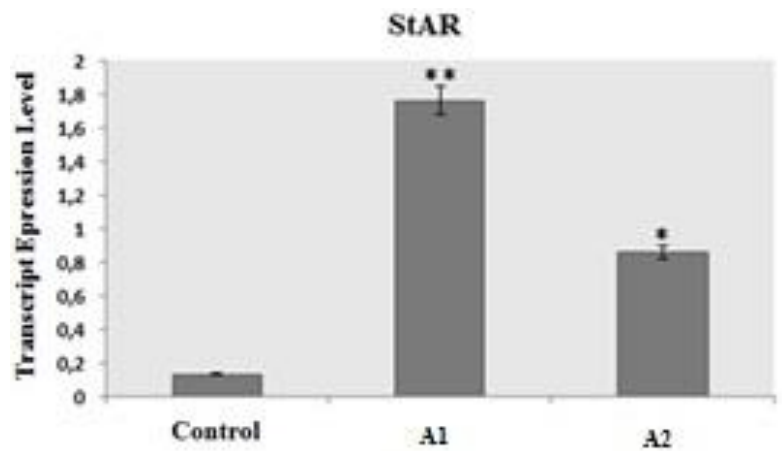

Figure 2a. StAR gene expression level relative to the control $(* * p<0.01, * p<0.05)$.

\section{CYP11A1}

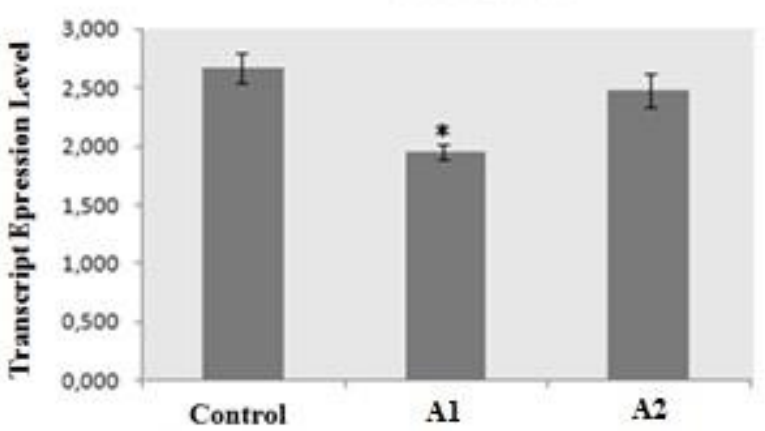

Figure 2b. Level of expression of the CYP11A1 gene relative to the control $(* p<0.05)$.

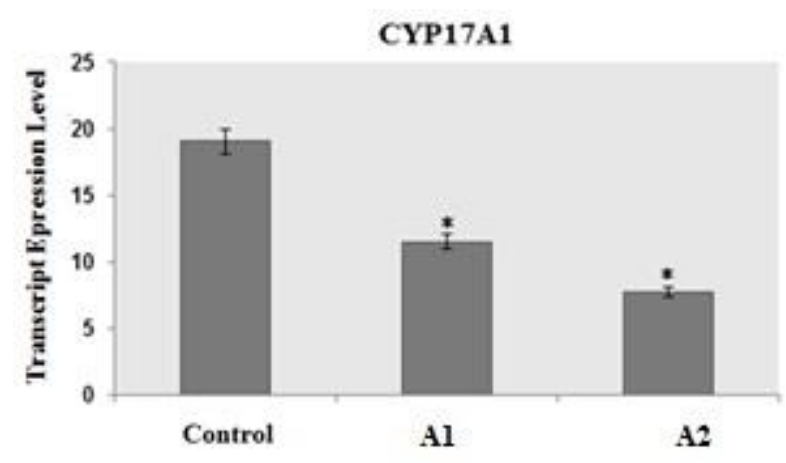

Figure 2c. Level of expression of the CYP17A1 gene relative to the control $\left({ }^{*} p<0.05\right)$.

The expression of genes encoding two converter enzymes in steroidogenesis; HSD3B and HSD17B was found to be slightly lower (but not significant) at lowdose, however RT-qPCR showed a decrease in their expression at high doses (HSD17B, 1.4 fold and HSD3B, 1.5 fold) $(p<0.05)$ (Figure $2 \mathrm{~d}$ and $2 \mathrm{e})$. Although GATA4 and Nurr77 transcription factors exhibited no significant changes in their expression at both doses, the expression of Steroidogenic factor 1 (SF-1) encoding a nuclear receptor was found to be decreased at low-dose (1.3 fold, $p<0.05)$ and high-dose (1.8 fold, $\mathrm{p}<0.01)$ (Figure 2f). 


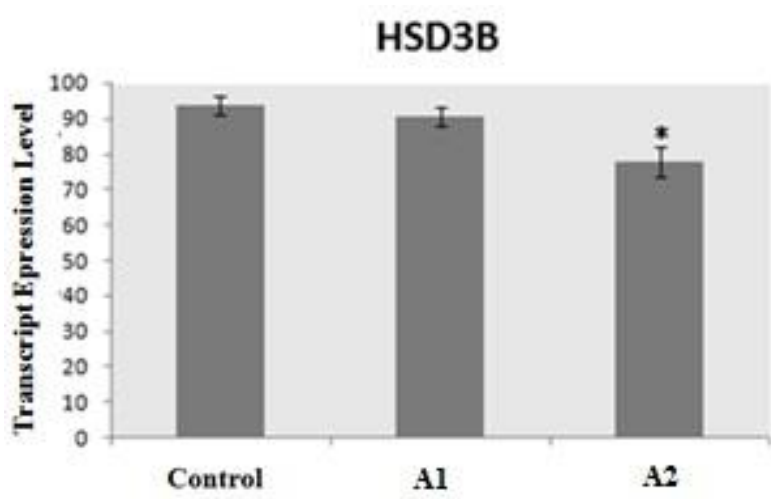

Figure 2d. Expression level of the HSD3B gene relative to the control $(* p<0.05)$.

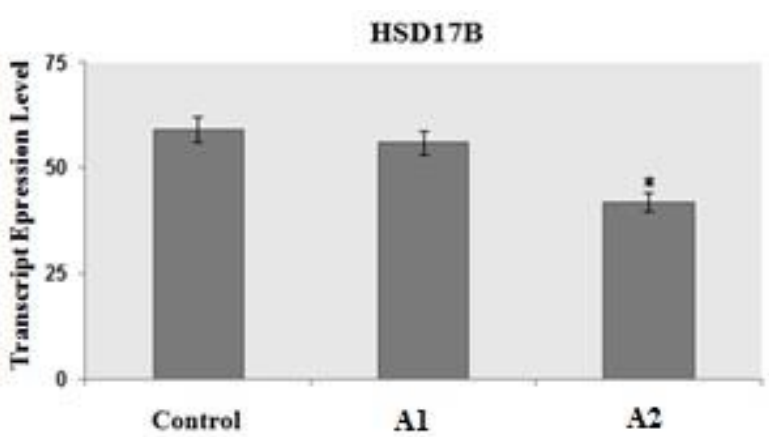

Figure 2e. Expression level of the HSD17B gene relative to the control $(* p<0.05)$.

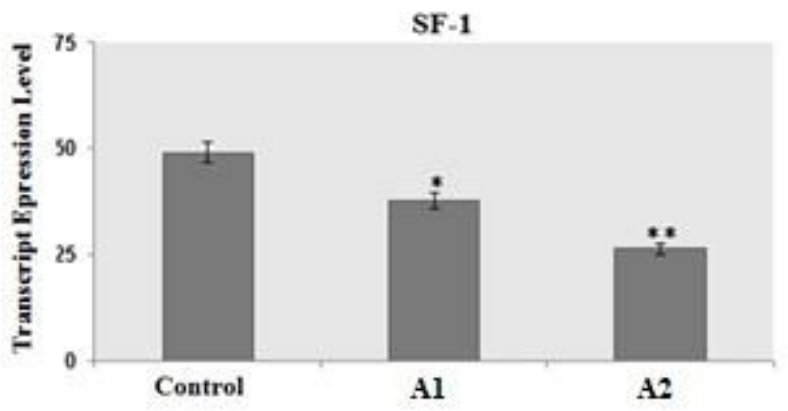

Figure 2f. Level of expression of the SF-1 gene relative to the control $\left(* * p<0.01,{ }^{*} p<0.05\right)$.

As indicated in previous studies, a significant reduction in Leydig cell number or abnormal perturbations in steroidogenic gene expression are significantly correlated with male infertility [16-17]. As similar with other toxic heavy metals, arsenic had detrimental effects on cell viability of TM3 Leydig cells in a dose-dependent manner. We also think that oxidative stress is probably attributed to reduction in TM3 cell viability $[6,13,19]$. In a study performed on TM4 Sertoli cells, which are responsible for maintenance of germ cells and successful completion of spermatogenesis, the cell viability of TM4 Sertoli cells exposed to $10-\mu \mathrm{M}$ arsenic trioxide for 48 hours was significantly decreased [17]. In another study, it was shown that wistar rats treated with arsenic showed a significant increase $(p<0.05)$ in the sperm abnormal morphology (head and tail) and decrease in viability [18]. In concordance with these findings, we concluded that testis tissue with various cells such as Leydig, Sertoli and sperms was sensitive to arsenic exposure and arsenicinduced cell viability reduction may cause male infertility.

Testosterone biosynthesis is essential for male reproductive system differentiation, continuation of spermatogenesis and the emergence of secondary male characters [20]. Previous studies have shown that arsenic exposure cause significant perturbation in the expression of genes in the pathway of steroidogenesis. For instance, approximately $60 \%$ reduction in expression of CYP11A1, CYP17A1, and HSD-3B genes occurred in mice left at $0.15 \mathrm{mg} / \mathrm{kg}$ arsenic exposure a day [19]. In the present study, we investigated the role of arsenic in the expression of steroidogenic key genes (StAR,

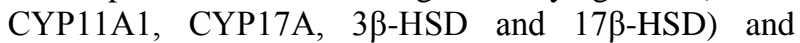
transcription factors (SF-1, NUR77 and GATA-4). In general, we found that there was a gradual reduction tendency in the expression of steroidogenic genes in TM3 Leydig cells exposed to arsenic [15]. StAR (Steroidogenic acute control protein) is an enzyme that allows the transport of cholesterol from the cytoplasm to the interior of the mitochondrial membrane, the precursor required for the synthesis of testosterone in the pathway of steroidogenesis [10, 20]. Many studies on toxic substances have shown that the toxic components reduce the expression of the StAR gene in the Leydig cell [7]. However, in some studies it has been found that toxic substances increase the expression of the StAR. For example, $1 \mu \mathrm{M}$ mono-(2-ethyl) phthalate affected expression ofvarious steroidogenesis genes in cultured rat testes, increasing the expression of the StAR gene [8]. For example, a study conducted by Liu et al., mouse Leydig cells were administered with zearelenon, which contaminates various foods and animal feeds, at a concentration of $5 \mu \mathrm{g} / \mathrm{ml}$ and expression of the StAR gene in the cells was increased [12]. In another study, Reitsma and colleagues observed that human adenosine carcinoma cells (H295R) used thiocapantine photoinitiator, which is used in food packages and contaminate food, and that the StAR expression increases [8]. In our study, StAR expression was also induced in Leydig cells exposed to arsenic and this finding is consistent with above-mentioned studies. Although the possible role of arsenic in the expression pattern of StAR remains uncertain, it was thought that arsenic may affects the transcription factors that regulate the expression of StAR. CYP11A1 is the enzyme-encoding gene that performs the pregnelona cycle of cholesterol, the first enzymatic reaction in the pathway of steroidogenesis [16]. CYP17A1 is a key enzyme in the steroidogenic pathway that produces progestins, mineralocorticoids, glucocorticoids, androgens, and estrogens. Several studies showed that toxic substances have drastic effects in the expression of CYP11A1 and CYP17A1 genes. A study conducted by Liu and colleagues demonstrated that the expression of CYP11A1 and CYP17A1 genes 
decreased when exposing mouse Leydig cells with zearelenon being $5 \mu \mathrm{g} / \mathrm{mL}$ [19]. Similarly, Chiou and colleagues performed arsenic thioxide administration on mice and found that the expression of the CYP11A1 and CYP17A1 genes decreased [5]. These findings are consistent with the present study, in which arsenicexposure leads the reduction gene expression levels. One possible explanation of the reduced of CYP11A1 and CYP17A1 genes observed here would be the decreased level of transcription factor, SF-1 gene that regulate expression of these genes. In this study, we also found that SF-1 expression level was decreased in Leydig cells exposed to arsenic. The HSD3B genes encodes the enzyme that converts pregnenolone to progesterone in the steroidogenesis pathway while HSD17B is the enzyme code that translates to the testosterone of androstenedione, the last enzymatic step in steroidogenesis. As similar with other steroidogenesis genes, toxic compounds also affect the expression of HSD17B and HSD3B. In a previous study, Liu et al. showed that the expression of the HSD17B wasdecreased in mouse Leydig cells treated with $5 \mu \mathrm{g} / \mathrm{ml}$ zealandone [19]. In another study conducted by Yang and colleagues [11], the expression of the HSD3B was found to be decreased in mouse Leydig cells exposed to T-2 toxin (mycotoxin) as correlated with our study. Taken together, our results showed that arsenic exposure reduce cell viability and cause significant perturbations in steroidogenic gene expressions. Although we partly reported the effects of arsenic toxicity in Leydig cell, a comprehensive study based on genome-wide transcriptome studies using microarray or RNA-Seq approaches are needed for further clarification of arsenic toxicity in testicular tissue.

\section{Conclusion}

In addition to heritable susceptibility, environmental toxicants, particularly heavy metals, seem to be responsible for causing the infertility in male through decreasing testicular cell viability and impairing gene expression involved in steroidogenesis. In this study, we found that arsenic toxicity in Leydig cells, which are the major source of testicular androgens, leads to cell viability loss and cause a perturbation in key steroidogenic genes, reflecting the possible role of arsenic in infertility and male reproductive system disorders.

\section{Acknowledgement}

This study was supported by the Scientific Research Projects Unit of Istanbul University. Project number 42756.

\section{Author's Contributions}

Tunahan Taşçi, Vahap Eldem, Melike Erkan: Drafted and wrote the manuscript, performed the experiment and result analysis.

Vahap Eldem, Melike Erkan: Assisted in analytical analysis on the structure, supervised the experiment's progress, result interpretation and helped in manuscript preparation.

\section{Ethics}

There are no ethical issues after the publication of this manuscript.

\section{References}

1. Lee, P, Lee, I. 2005. Oxidative stress mediates sodium arseniteinduced expression of heme oxygenase-1, monocyte chemoattractant protein-1, and interleukin-6 in vascular smooth muscle cells. Toxicological sciences; 85.1: 541-550.

2. Li, W.R, Chen, L, Chang, Z.J, Xin, H, Liu, T, Zhang, Y.Q, Xin, Z.C. 2011. Autophagic deficiency is related to steroidogenic decline in aged rat Leydig cells. Asian journal of andrology ;881:13-6

3. Chiou, T.J, Chu, S.T, Tzeng, W.F, Huang, Y.C, Liao, C.J. 2008 Arsenic trioxide impairs spermatogenesis via reducing gene expression levels in testosterone synthesis pathway. Chemical research in toxicology; 21.8: 1562-1569.

4. El-Demerdash, Fatma, M, Mokhtar, I.Y. 2009. Ameliorating effect of curcumin on sodium arsenite-induced oxidative damage and lipid peroxidation in different rat organs. Food and Chemical Toxicology; 47.1: 249-254.

5. Mathur, N, Pandey, G, Jain, G.C. 2010. Male reproductive toxicity of some selected metals: A review. Journal of biological sciences; 10.5: $396-404$

6. Chang, S, Jin, B, Youn, P, Park, C, Park, J.D, Ryu, D.Y. 2007. Arsenic-induced toxicity and the protective role of ascorbic acid in mouse testis. Toxicology and applied pharmacology; 218.2: 196203.

7. Simeonova, P.P, Wang, S, Toriuma, W, Kommineni, V, Matheson, J, Unimye, N, Lusteri, M.I. 2000. Arsenic mediates cell proliferation and gene expression in the bladder epithelium: association with activating protein-1 transactivation. Cancer research; 60.13:3445-3453.

8. Reitsma, M, Bovee, T.F, Peijnenburg, A.A, Hendriksen, P.J, Hoogenboom, RL, Rijk, J.C, 2013, Endocrine-disrupting effects of thioxanthone photoinitiators. Toxicological Sciences, 132(1), 64 74

9. Wang, R.S, Yeh, S, Tzeng, C.R, Chang, C. 2009. Androgen receptor roles in spermatogenesis and fertility: lessons from testicular cell-specific androgen receptor knockout mice. Endocrine reviews; 30.2: 119-132.

10. Camats, N, Audí, L, Fernández-Cancio, M, Andaluz, P, Mullis, $\mathrm{P}$ E, Carrascosa, A, Flück, C.E. 2015. LRH-1 May Rescue SF-1 Deficiency for Steroidogenesis: An in vitro and in vivo Study. Sexual development; 9.3: 144-154.

11. Payne, A.H, Hales, D.B. 2004. Overview of steroidogenic enzymes in the pathway from cholesterol to active steroid hormones. Endocrine reviews; 25.6: 947-970.

12. Liu, Q, Wang, Y, Gu, J, Yuan, Y, Liu, X, Zheng, W, Bian, J. 2014. Zearalenone inhibits testosterone biosynthesis in mouse Leydig cells via the crosstalk of estrogen receptor signaling and orphan nuclear receptor Nur77 expression. Toxicology in Vitro, 28(4), $647-$ 656.

13. Kim, Y.J, Chung, J.Y, Lee, S.G, Kim, J.Y, Park, J.E, Kim, W.R, Kim, J.M. 2011. Arsenic trioxide-induced apoptosis in TM4 Sertoli cells: the potential involvement of p21 expression and p53 phosphorylation. Toxicology; 285.3: 142-151. 
14. Khan, S, Telang, A.G, Malik, J.K. 2013. Arsenic-induced oxidative stress, apoptosis and alterations in testicular steroidogenesis and spermatogenesis in wistar rats: ameliorative effect of curcumin WJPP ; 2: 33-48.

15. Chen, C.J, Wang, S.L, Chiou, J.M, Tseng, C.H, Chiou, H.Y Hsueh, Y.M, Lai, M.S. 2007. Arsenic and diabetes and hypertension in human populations: a review. Toxicology and applied pharmacology; 222.3: 298-304.

16. Payne, A.H, Youngblood, G.L. 1995. Regulation of expression of steroidogenic enzymes in Leydig cells. Biology of reproduction; 52.2: $217-225$

17. Andric, S.A, Janjic, M.M, Stojkov, N.J, Kostic, T.S. 2007. Protein kinase G-mediated stimulation of basal Leydig cell steroidogenesis. American Journal of Physiology-Endocrinology and Metabolism; 293.5: E1399-E1408.
18. Boonchai, W, Walsh, M, Cummings, M, Chenevix-Trench, G. 2000. Expression of p53 in arsenic-related and sporadic basal cell carcinoma. Archives of dermatology; 136.2: 195-198.

19. Yang, J. Y, Zhang, Y.F, Liang, AM, Kong, XF, Li, Y.X, Ma, K.W, Qiao, X.L. 2009, Toxic effects of T-2 toxin on reproductive system in male mice, Toxicology and Industrial Health, 29, 1166-1171M, Bovee, TF, Peijnenburg, AA, Hendriksen, PJ, Hoogenboom, RL, Rijk, JC. 2013. Endocrine-disrupting effects of thioxanthone photoinitiators. Toxicological Sciences; 132.1: 64-74.

20. Yildizbayrak, N, Erkan, M. 2018. Acrylamide disrupts the steroidogenic pathway in Leydig cells: possible mechanism of action. Toxicological \& Environmental Chemistry; 100(2), 235246. 